\title{
Objective assessment of visual acuity by induction of optokinetic nystagmus
}

\author{
I. LEWKONIA
}

Moorfields Eye Hospital, London, W.C.I

Optokinetic nystagmus is the term applied to the nystagmus evoked by a succession of moving objects passing before the eyes (Brain, 1962). It has proved useful as a diagnostic tool in the examination of patients with neurological disease (Cogan, 1956; Huber, 1961 ; Smith, 1963; Walsh, 1957). Methods of inducing and suppressing optokinetic nystagmus have also been used as the basis for objective testing of the visual acuity (Dayton, Jones, Aiu, Rawson, Steele and Rose, 1964; Goldmann, 1943; Gorman, Cogan, and Gellis, 1957; Kiff and Lepard, 1966; Ohm, 1953; Reinecke and Cogan, 1958; Schmidt, 1956; Schwarting, 1954; Tauber and Koffler, 1966; Voipio, 1961; Wolin and Dillman, 1964). However, none of these methods of assessing visual acuity has become generally established for routine testing largely because of the complexity of the apparatus. The technique to be described is simple to perform and gives rapid and acceptable results.

Apparatus (Figs I and 2, overleaf)

This consists essentially of two parts, namely a cylinder $10^{\prime \prime}$ high and $6^{\prime \prime}$ in diameter, and a turntable, in front of which is mounted a frame (Figs $\mathrm{I}$ and 2). The cylinder, which is made from an acrylic material and is painted white, revolves on the turntable. Marked on it are six rows of twelve equally spaced black dots of graduated size, ranging in diameter from 0.5 to $7 \mathrm{~mm}$. The largest dots form the highest row and they serve as a gross test. From the second to the sixth row the dots increase in size from above downwards (Fig. I). The sizes of the dots were determined by trial and error. The Table demonstrates the lack of correlation between the accorded range of visual acuity for a given size of dot, and the angle that the dot subtends at the working distance. The turntable was adapted from an old record player. It can be made to rotate at $16,33,45$, and $78 \mathrm{revs} / \mathrm{minute}$, but in practice the optimum speed of rotation was found to be 16 revs/minute.

A framework constructed of horizontal strips of metal was built onto the front of the turntable platform. Six of these strips are hinged and correspond in position to the rows of dots on the cylinder. With this arrangement it is possible to open one of the hinges and reveal one row of dots at a time to a patient sitting in front of the apparatus (Fig. 2). The front of the cylinder is illuminated by two $3^{3}$ watt tungsten strips placed vertically behind the frame. A working distance of I metre has been chosen as the most suitable for use with adults and a $\mathrm{I}$ metre length of cord fixed to the front of the turntable is used to determine the correct viewing position.

The apparatus was standardized using adult patients, chosen at random, who were attending at Moorfields Eye Hospital, High Holborn. Their visual acuity was first checked in the usual manner using Snellen's chart at a distance of $6 \mathrm{~m}$. They were then seated I metre away from the apparatus and the induction of optokinetic nystagmus by presenting revolving dots of varying sizes was determined. 26 I comparisons were made and the results are presented in Figs 3 and 4 (overleaf). 


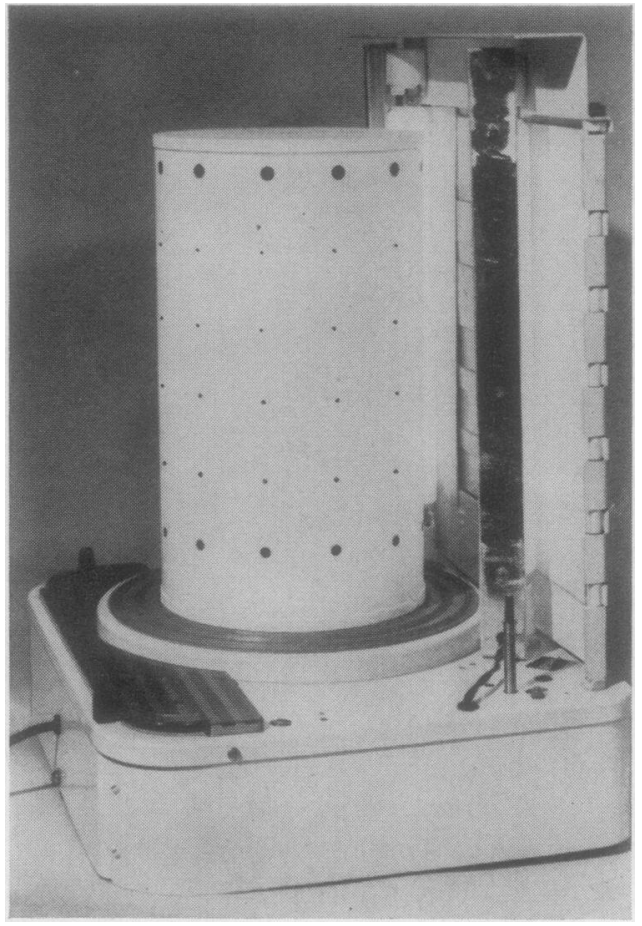

FIG. I Apparatus, showing dots of various sizes which can be shown to the patient by opening one of six hinged strips

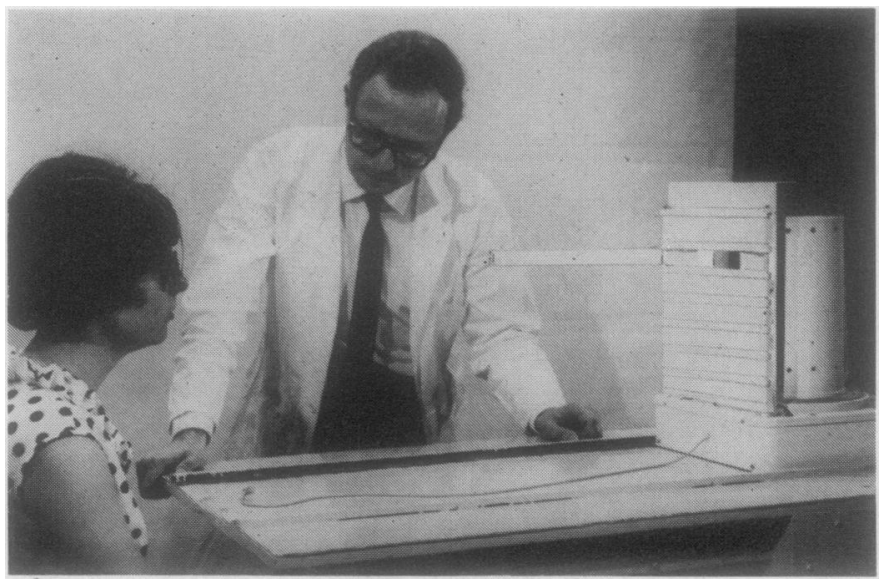

FIG. 2 Apparatus in use, showing second door open

\section{Procedure for assessing visual acuity}

Each eye is tested separately. Patients over the age of 40 years are arbitrarily given a $+\mathrm{I}$ dioptre $N$ lens to compensate for presbyopia. The largest dots (Line I) are presented first, and the patient is N told to look at the cylinder. In most cases optokinetic nystagmus is produced. This first step helps the patient to understand the basis of the test and further instruction is usually unnecessary. The 0 smallest dots (Line 2) are then displayed and the observer watches for optokinetic nystagmus. If it $\bar{\varnothing}$ is not produced, dots of increasing size are presented until the nystagmus becomes evident. If $\stackrel{\mathscr{N}}{\rightarrow}$ nystagnuus is not produced by the largest dots at a distance of $\mathrm{I}$ metre, the apparatus is moved closer to the patient until the reflex is elicited. In carrying out the test, optokinetic nystagmus is judged to 
(3)

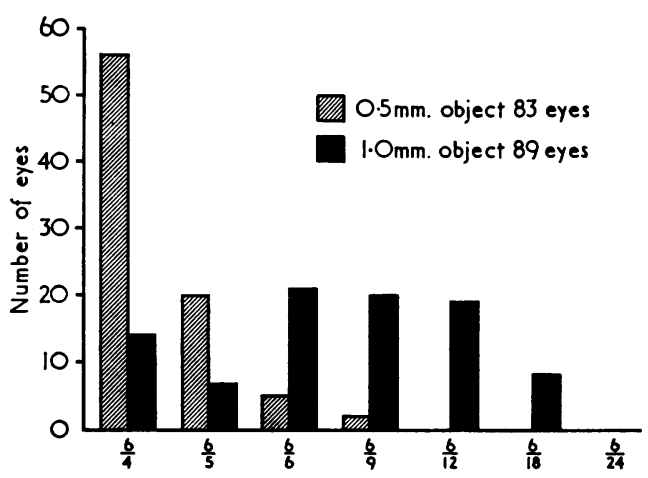

(4)

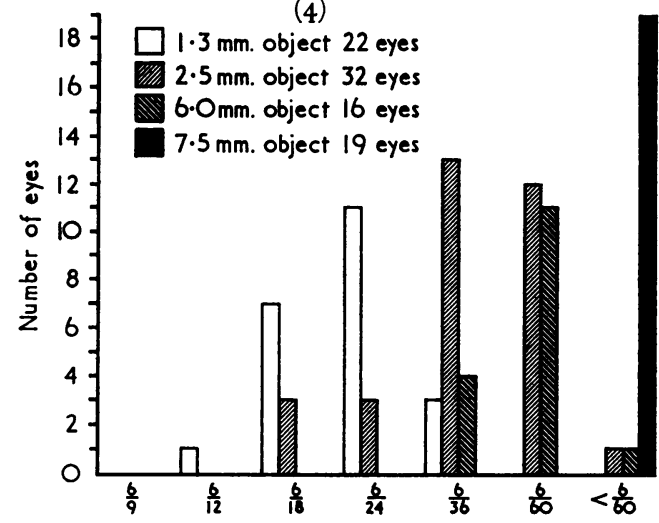

FIG. 3 Production of optokinetic nystagmus in eyes of known visual acuity using $0.5 \mathrm{~mm}$. and I $\mathrm{mm}$. test objects

FI G. 4 Production of optokinetic nystagmus in eyes of known visual acuity using I $\cdot 3 \mathrm{~mm} ., 2 \cdot 5 \mathrm{~mm}$., $6 \cdot 0 \mathrm{~mm}$., and $7.5 \mathrm{~mm}$. test objects

be present if a rhythmical and sustained to and fro oscillation of the eyes occurs within 3 seconds of revealing the dots. Irregular roving movements are discounted. In practice many patients admit to seeing the dots before the nystagmus is evident but this in no way invalidates the results as the same would apply in the standardization of the machine.

\section{Results}

It proved possible to assign a range of visual acuity for each row of dots (see Table).

Table Sizes of dots and accorded ranges of acuity

\begin{tabular}{lll}
\hline $\begin{array}{l}\text { Diameter of object } \\
\text { to nearest } 0 \cdot 1 \mathrm{~mm} .)\end{array}$ & $\begin{array}{l}\text { Angle subtended } \\
\text { at } \mathrm{I} m .\end{array}$ & $\begin{array}{l}\text { Range of visual } \\
\text { acuity }\end{array}$ \\
\hline $0 \cdot 5$ & $1 \cdot 7^{\prime}$ & $\frac{6}{5}$ and better \\
$1 \cdot 0$ & $3 \cdot 4^{\prime}$ & $\frac{6}{12}$ and better \\
$1 \cdot 3$ & $4 \cdot 3^{\prime}$ & $\frac{6}{24}\left(\frac{6}{18}-\frac{6}{36}\right)$ \\
$2 \cdot 5$ & $8 \cdot 6^{\prime}$ & $\frac{6}{36}\left(\frac{6}{24}-\frac{6}{60}\right)$ \\
$6 \cdot 0$ & $20 \cdot 6^{\prime}$ & $\frac{6}{36}-\frac{6}{60}$ \\
$7 \cdot 5$ & $25 \cdot 8^{\prime}$ & Worse than $\frac{6}{60}$ \\
\hline
\end{tabular}

When the results are compared with the allotted range the overall accuracy is found to be 88 per cent. Taking each row separately, at least 80 per cent. of the results are within the allotted range. It has already been noted that no close correlation was found between the range of visual acuity and the angle subtended by the dot. 


\section{Comment}

The production of optokinetic nystagmus with dots of a particular size allows the observer to conclude that the visual acuity is at least as good as the allotted range. If it is not produced, one cannot definitely infer that the patient has a reduced acuity. Failure to fix on the rotating targets will obviously give erroneous results. Hence a negative finding does not exclude the possibility of good visual acuity. In practice, very few of the patients who were used to standardize the instrument failed to produce nystagmus.

This method of determining visual acuity by optokinetic nystagmus has only a limited application to adults, although it may be useful when there is a language problem or the patient is thought to be malingering. Its particular application is to the assessment of the visual acuity of children who are too young to use Snellen's charts. It is easier and quicker than the "E" and other similar tests. The fact that a range of visual acuity is measured rather than a particular line in terms of the Snellen's connotation is of little significance to the paediatric ophthalmologist.

Initial tests with young children, including infants, have been very encouraging, although it will probably be necessary to modify the scale for use at distances less than 1 metre so that young children under the age of 12 months whose attention is usually not attracted to even the largest dots at that distance, can be assessed. It is hoped to record a series of results in young children at some future date.

\section{Summary}

A method of assessing visual acuity objectively by the induction of optokinetic nystagmus is described and the results are presented.

I wish to thank Prof. E. S. Perkins and Dr. R. A. Weale for their help and permission to work in their departe⿳⺈, ments. I am also indebted to Mr. K. C. Wybar for his suggestions and encouragement and for allowing me access to his patients at Great Ormond Street Children's Hospital. I particularly wish to express my gratitude to Mr. Downing, who helped in the construction of the machine, and to Mr. Tarrant and other members of the Illustration Department of the Institute of Ophthalmology for their assistance.

\section{References}

BRAIN, W. R. (1962) "Diseases of the Nervous System", 6th ed., p. 69. Oxford University Press, London

COGAN, D. G. (1956) "Neurology of the Ocular Muscles", 2nd ed., p. i94. Thomas, Springfield, Ill. DAYton, G. O., JONes, M. H., AIU, P., RAWSon, R. A., Steele, B., and rose, M. (1964) Arch. Ophthal. (Chicago), 7r, 865

Goldmann, H. (1943) Ophthalmologica (Basel), ro5, 240

gorman, J. J., COGAN, D. G., and Gellis, s. S. (1957) Pediatrics, 19, 1088

HUBER, A. (I96I) “Eye Symptoms in Brain Tumors", ist ed., pp. 67-68; 73. Mosby, St. Louis KIFF, R. D., and LEPARD, C. (I966) Arch. Ophthal. (Chicago), 75, 631

онм, J. (1953) "The Objective Testing of Visual Acuity by Optokinetic Nystagmus". Enke,

Stuttgart

REINECKe, R. D., and COGAN, D. G. (1958) A.M.A. Arch. Ophthal., 6o, 418

sCHMIDT, T. (1956) Amer. F. Ophthal., 42, 123

SGHWARTING, B. H. (1954) Ibid., 38, 714

SMITH, J. L. (1963) “Optokinetic Nystagmus”, Thomas, Springfield, Ill.

TAUBER, E. S., and KOFFLER, s. (1966) Science, 152, 382

voIPIO, H. (I96I) Acta ophthal. (Kbh.), Suppl. 66

WALSH, F. B. (1957) "Clinical Neuro-Ophthalmology", 2nd ed., p. 266. Williams and Wilkins,

Baltimore

wolin, L. R., and Dillman, A. (1964) Arch. Ophthal. (Chicago), 71, 822 